\title{
Youth dietary intake and weight status: Healthful neighborhood food environments enhance the protective role of supportive family home environments
}

\section{Citation}

Berge, Jerica M., Melanie Wall, Nicole Larson, Ann Forsyth, Katherine W. Bauer, and Dianne Neumark-Sztainer. 2014. "Youth Dietary Intake and Weight Status: Healthful Neighborhood Food Environments Enhance the Protective Role of Supportive Family Home Environments." Health \& Place 26 (March): 69-77. doi:10.1016/j.healthplace.2013.11.007. http://dx.doi.org/10.1016/ j.healthplace.2013.11.007.

\section{Published Version}

doi:10.1016/j.healthplace.2013.11.007

\section{Permanent link}

http://nrs.harvard.edu/urn-3:HUL.InstRepos:14442090

\section{Terms of Use}

This article was downloaded from Harvard University's DASH repository, and is made available under the terms and conditions applicable to Open Access Policy Articles, as set forth at http:// nrs.harvard.edu/urn-3:HUL.InstRepos:dash.current.terms-of-use\#OAP

\section{Share Your Story}

The Harvard community has made this article openly available.

Please share how this access benefits you. Submit a story.

\section{Accessibility}




\title{
Youth Dietary Intake and Weight Status: Healthful Neighborhood Food Environments Enhance the Protective Role of Supportive Family Home Environments
}

\author{
Jerica M. Berge, PhD, MPH, LMFT ${ }^{1}$, Melanie Wall, $\mathrm{PhD}^{2}$, Nicole Larson, PhD, MPH, $\mathbf{R D}^{3}$, \\ Ann Forsyth, $\mathrm{PhD}^{4}$, Katherine W. Bauer, $\mathrm{PhD}, \mathrm{MS}^{5}$, and Dianne Neumark-Sztainer, PhD, RD, \\ $\mathrm{MPH}^{3}$ \\ ${ }^{1}$ University of Minnesota Medical School, Department of Family Medicine and Community Health, \\ Minneapolis, MN \\ 2Division of Biostatistics in the Department of Psychiatry and Department of Biostatistics in the \\ Mailman School of Public Health, Columbia University, New York, NY \\ ${ }^{3}$ University of Minnesota, Division of Epidemiology and Community Health, Minneapolis, MN \\ ${ }^{4}$ Urban Planning and Design, Harvard University, Cambridge, MA \\ ${ }^{5}$ Temple University, Department of Public Health and Center for Obesity Research and \\ Education, Philadelphia, PA
}

\begin{abstract}
The aim of this study is to investigate individual and joint associations of the home environment and the neighborhood built environment with adolescent dietary patterns and body mass index (BMI) z-score. Racially/ethnically and socioeconomically diverse adolescents $(n=2682 ; 53.2 \%$ girls; mean age 14. 4 years) participating in the EAT 2010 (Eating and Activity in Teens) study completed height and weight measurements and surveys in Minnesota middle and high schools. Neighborhood variables were measured using Geographic Information Systems data. Multiple regressions of BMI z-score, fruit and vegetable intake, and fast food consumption were fit including home and neighborhood environmental variables as predictors and also including their interactions to test for effect modification. Supportive family environments (i.e., higher family functioning, frequent family meals, parent modeling of healthful eating) were associated with higher adolescent fruit and vegetable intake, lower fast food consumption, and lower BMI z-score. Associations between the built environment and adolescent outcomes were fewer. Interaction results, although not all consistent, indicated that the relationship between a supportive family environment and adolescent fruit and vegetable intake and BMI was enhanced when the neighborhood was supportive of healthful behavior. Public health interventions that simultaneously improve both the home environment and the neighborhood environment of adolescents may have a greater impact on adolescent obesity prevention than interventions that address one of these environments alone.
\end{abstract}

(C) 2013 Elsevier Ltd. All rights reserved.

Address for correspondence: Jerica M. Berge, PhD, LMFT, Department of Family Medicine and Community Health, Phillips Wangensteen Building, 516 Delaware Street SE, Minneapolis, MN 55455, Voice: 612-626-3693, mohl0009@umn.edu.

Publisher's Disclaimer: This is a PDF file of an unedited manuscript that has been accepted for publication. As a service to our customers we are providing this early version of the manuscript. The manuscript will undergo copyediting, typesetting, and review of the resulting proof before it is published in its final citable form. Please note that during the production process errors may be discovered which could affect the content, and all legal disclaimers that apply to the journal pertain.

Disclosures: None of the authors have conflicts of interest to declare. 


\section{Keywords}

Family Functioning; Adolescents; Obesity; Dietary Intake; Physical Activity; Family Meals

\section{INTRODUCTION}

While obesity rates among adolescents have started to plateau for some racial/ethnic groups, ${ }^{1-5}$ the prevalence of adolescent obesity remains at an all-time high posing a major public health concern. ${ }^{4,5} \mathrm{~A}$ related concern is the dietary intake of adolescents. Fewer than 1 in 10 American adolescents meet the daily recommendation for fruit or vegetable intake. ${ }^{6,7}$ About 33 percent of children and adolescents in the United States consume fast food on a typical day, and intake increases with age. ${ }^{8,9}$ Furthermore, it is estimated that on average adolescents visit fast food restaurants approximately twice a week. ${ }^{10}$ Although previous research has provided a good understanding of individual-level risk (e.g., fast food consumption) and protective factors (e.g. fruit and vegetable intake) that are associated with adolescent obesity, the relationship between multiple contexts, such as the home food environment (e.g., family meals, family functioning, modeling of health behaviors) and the neighborhood built environment (e.g., density of fast food, distance to closest supermarket) has been largely overlooked in relation to adolescent dietary intake patterns and obesity. Because these environments co-exist in adolescents' lives, it is important to understand the individual and joint relationships between the home environment and the neighborhood built environment and adolescent obesity in order to identify which combinations of factors within these two environments are associated with increased or decreased protection against adolescent obesity. Futhermore, NIH and other entities have called for such multi-contextual analyses to improve our understanding of the complex systems in which people live and by which they are influenced. ${ }^{11}$

The majority of previous research has examined associations between single contexts, such as, the home food environment or the built environment, and adolescent weight and weightrelated outcomes. Prior research on the home environment has shown associations between a healthful family home environment and more healthful dietary intake, less fast food consumption and a lower prevalence of overweight/obesity in adolescents. ${ }^{12-17}$ Specifically, associations between characteristics of the home environment, such as parent modeling and encouraging of healthful eating, frequent family meals and high family functioning have been identified as protective, although not all associations are found consistently. ${ }^{13,15-26}$ Less research has examined associations between neighborhood characteristics (e.g. food access, fast food density) and youth health behaviors and the findings have been mixed. For example, some studies have shown that close proximity/access to convenience stores and poor access/proximity to supermarkets is associated with increased overweight/obesity in youth and low fruit and vegetable intake, whereas other studies have shown a positive association between having fresh fruits and vegetables available in small food stores (i.e., convenience store) that are close to residential households and higher intake of fruits and vegetables in adolescents, and still other studies have shown no association or minimal relationships between environmental variables and adolescent weight and weight-related behaviors. ${ }^{27-31}$ Thus, in general, previous research has found that the home environment is associated with dietary intake and weight status in adolescents, while associations between the neighborhood environment and similar outcomes are less consistent. A next step is to examine both the independent and joint relationships between the family home environment and the neighborhood built environment to characterize the relationships between these factors and to identify key factors across multiple contexts in the lives of adolescents that contribute to adolescent fruit and vegetable intake, fast food consumption, and weight status. 
The Ecological framework ${ }^{32,33}$ supports the importance of examining the multiple contexts within which adolescents' reside and are influenced in order to more clearly understand potential underlying mechanisms of adolescent obesity. Specifically, the Ecological framework indicates that there are multiple contexts of influence on adolescents' weightrelated behaviors, such as one's own individual behavior (e.g., fruit and vegetable intake), the home environment (e.g., family functioning, modeling of health behaviors, availability of healthful foods), interpersonal relationships (i.e., communication, connectedness), and neighborhood (e.g., built environment such as fast food establishments) and larger community forces (i.e., crime, politics). For example, an adolescent who lives in a home where there is higher family functioning (i.e., acceptance, problem solving), family meals eaten together, and who also lives in a neighborhood that has fewer fast food establishments or convenience stores close by would be expected to have lower weight status and healthier eating behaviors than an adolescent without this accumulation of supportive environments. Thus, being able to examine all of these factors independently and in combination will highlight more clearly the role of the multiple influences on adolescent weight and weightrelated behaviors. The current study's design, measures, research questions and hypotheses are guided by this theoretical framework.

The main hypothesis of this paper is: adolescents who experience both health-supporting neighborhoods (i.e., fewer fast food establishments, fewer convenience stores, nearby supermarkets) and family environments (i.e., higher family functioning, more family meals, parent encouraging and modeling of healthful eating) will have a higher intake of fruits and vegetables, lower fast food consumption and lower BMI. Examining this joint association will allow for identifying whether and how the surrounding built environment moderates the association between a healthful home environment and healthful dietary intake and risk for overweight/obesity in adolescents. Results from the current study are expected to inform future intervention research by guiding the implementation of multi-level interventions that simultaneously target family and neighborhood variables.

\section{METHODS}

\section{Study Design and Population}

Data were drawn from EAT 2010 (Eating and Activity in Teens), a population-based study examining environmental and individual determinants of adolescents' dietary intake, physical activity, weight control behaviors, and weight status. The study population includes adolescents from 20 public middle schools and high schools in the Minneapolis/St. Paul metropolitan area of Minnesota, which serve socioeconomically and racially/ethnically diverse communities. There were 2,682 adolescents who completed surveys and anthropometric measures during the 2009-2010 academic year and for whom Geographic Information Systems (GIS) data were available to describe their neighborhood environments. Mean participant age was 14.5 years $(\mathrm{SD}=2.0) ; 45.1 \%$ were in middle school (6th-8th grades) and 54.9\% were in high school (9th-12th grades). Participants were equally divided by gender (53.5\% girls). Racial/ethnic backgrounds represented were: $18.7 \%$ white, 29.2\% African American or Black, 20.1\% Asian American, 17.1\% Hispanic, 3.4\% Native American, and $11.5 \%$ mixed or other. Participants were distributed across five socioeconomic status (SES) strata: $29.4 \%$ low SES, $24.3 \%$ low-middle SES, $33.3 \%$ middle SES, 6.4\% upper-middle SES, and $2.8 \%$ high SES.

\section{Adolescent Assessments: Survey Development and Measures}

The EAT 2010 survey is a 235-item self-report instrument assessing a range of factors of potential relevance to weight status and weight-related behaviors among adolescents. Survey development was guided by a review of previous Project EAT surveys ${ }^{34,35}$ to identify the 
most salient items; a theoretical framework, which integrates an Ecological perspective with Social Cognitive Theory; ${ }^{36,37}$ expert review by professionals from different disciplines; and pilot testing with adolescents $(n=56)$ for clarity, readability and relevance of the survey items. After revisions, the survey was additionally pilot tested with a different sample of adolescents $(n=129)$ to examine the test-retest reliability of measures over a one-week period. Reliability results were used to make final changes to the survey.

Family functioning-Six items were drawn from the general functioning scale of the Family Assessment Device (FAD) ${ }^{38,39}$ to measure overall family functioning. The general functioning scale on the $F A D$ measures structural and organizational properties of the family group and the patterns of transactions among family members which have been found to distinguish between "healthy" and "poor functioning" families. Six dimensions of family functioning were assessed including: problem solving, communication, roles, affective responsiveness, affective involvement, and behavior control. Adolescents were asked, "How strongly do you agree with the following statements? For these questions, think about your family in general (including your parents and your brothers and sisters). (a) Family members are accepted for who they are; (b) Making decisions is a problem for the family; (c) We don't get along well together; (d) We can express feelings to each other; (e) Planning family activities is difficult because we misunderstand each other; (f) We confide in each other (By 'confide' we mean to trust your family members enough to tell them something that is important to you)." The response options included: strongly disagree, somewhat disagree, somewhat agree, and strongly agree. The responses were assigned values 1-4 and all statements were converted to the positive form before the values were summed. The range of responses for this scale was 6-24, with higher scores representing healthier family functioning (Scale alpha $=0.70)$.

Frequency of family meals-To assess family meal frequency, adolescents were asked: "During the past seven days, how many times did all, or most, of your family living in your house eat a meal together?" Response options included: never, one to two times, three to four times, five to six times, seven times, and more than seven times (Test-retest $r=0.63$ ). The highest two categories were collapsed and responses were coded numerically as $0,1.5$, 3.5, 5.5, and 7 .

Parent encouraging healthful eating-Adolescents' perception of whether their parents encouraged them to eat healthfully was measured by asking separately for each parent, "My mother [father] encourages me to eat healthy foods." Response options included: not at all, a little bit, somewhat, or very much (Test-retest mother $r=0.47$, father $r$ $=0.66$ ). The mean of the adolescent's responses for both mothers and fathers were summed together to create one item (Scale alpha $=0.58$ ).

Parent modeling healthful eating-Adolescents' perception of their parents' modeling healthful eating was adapted from a previous measure. ${ }^{40}$ Adolescents were asked the following questions for each parent: (1) "My mother [father] eats a lot of fruit; (2) My mother [father] eats vegetables at dinner; and (3) My mother [father] drinks milk at dinner." Response options included: never, rarely, sometimes, or on a regular basis (Test-retest mother $r=0.67-0.70$, father $r=0.52-0.69$ ). The means of each adolescent's responses for both mothers and fathers were summed together to create one item (Scale alpha $=0.71$ ).

Frequency of eating meals as a family at a restaurant-The frequency of family eating out was assessed by adolescent self-report. Adolescents were asked, "In the past week, how many times did all, or most, of your family living in your household eat out 
together at a restaurant?" Response options were ranged from never, 1 time, 2 times, or three or more times (Test-retest $\mathrm{r}=0.55$ ).

Adolescent fruit/vegetable intake—Dietary intake was assessed with the 149-item Youth and Adolescent Food Frequency Questionnaire (YAQ). ${ }^{41}$ For fruit and vegetable intake, daily servings were defined as the equivalent of one-half cup. Validity and reliability of the YAQ have been tested among a random sample of children (9-18 years) of participants in the Nurse's Health Study and found to be within acceptable ranges for dietary assessment tools. ${ }^{41,42}$ Test-retest correlations between two YAQs over a one-year period were 0.49 for fruit, and 0.48 for vegetables. Responses to questions on the frequency of intake of fruits and vegetables (excluding potatoes) were summed to assess average total daily intake.

Adolescent fast food consumption-Adolescent fast food intake was assessed with the question: "In the past month, how often did you eat something from the following types of restaurants (include take-out and delivery)?" Five separate categories of fast-food restaurants (burger-and-fries, fried chicken, Mexican, pizza, and sandwich/sub restaurants) were listed, and for each one response options were never/rarely, 1-3 times per month, 1-2 times per week, 3-4 times per week, 5-6 times per week, and 1+ times per day. Responses were scored to times/week respectively as: $0,0.5,1.5,3.5,5.5$, and 7 and were summed across the five fast-food restaurant types (Test retest $=0.49$ ). To prevent outlying values from influencing results, responses were truncated at 21 times per week (i.e., 3 fast food meals per day).

Adolescent body mass index (BMI) z-score-Students' height and weight measurements were taken at school by trained research staff in a private area with standardized equipment and procedures. Students were asked to remove shoes and outerwear (e.g., heavy sweaters). BMI values were calculated according to the following formula: weight $(\mathrm{kg}) /$ height (meters) ${ }^{2}$ and gender- and age-specific percentiles were determined using reference data from the Centers for Disease Control growth tables in order to calculate BMI z-scores. BMI z-scores represent the number of SDs a participant's BMI is above (positive) or below (negative) the standard population mean. ${ }^{43}$

Covariates-Race/ethnicity, socio-economic status (SES), and age were assessed by selfreport as part of the EAT 2010 survey. ${ }^{44}$ Racelethnicity was assessed with the question: "Do you think of yourself as...? (1) White, (2) Black or African American, (3) Hispanic or Latino, (4) Asian American, (5) Native Hawaiian or Pacific Islander, (6) American Indian or Native American, or (7) Other". Since only 35 adolescents reported "Hawaiian or Pacific Islander" they were coded as "mixed/other". Classification tree methodology ${ }^{36}$ was used to generate five categories of SES (Low SES, Low-Mid SES, Middle SES, Mid-High SES, High SES $)^{27}$. The prime determinant of SES was the higher education level of either parent. Subsidiary variables were family eligibility for free/reduced lunch, family receipt of public assistance, and parent employment status. ${ }^{45,46}$

\section{Neighborhood Environment Assessment: GIS Data Sources and Variable Definition}

GIS data sources were used to examine access to fast-food restaurants, convenience stores, and supermarkets/super centers within residential neighborhood environments. ArcGIS Version 9.3.1 (Esri, Redlands, California, 2009) was used for geocoding each participant's home address and commercial database (accessed through Esri Business Analyst, 2010) ${ }^{47}$ were used to create distance and density variables describing food access. Each neighborhood food access variable was created uniquely for each participant using street network buffers centered at the participant's home address. All distance variables were 
derived using the automobile-accessible road network between a participant's home and the nearest destination. Additional details on the protocols for deriving neighborhood environment variables have been previously published. ${ }^{48}$

Presence of a nearby fast food restaurant and restaurant density-The North American Industrial Classification System (NAICS) codes 722110, 722211, 722212, and 722213 were used to identify restaurants and both chain names and 18 key words (e.g., take out, fried, pizza) were used to classify fast-food restaurants. A dichotomous measure was derived and taken to equal one when the distance via the road network to the nearest fastfood restaurant was less than $1200 \mathrm{~m} .{ }^{49,50}$ Density of fast-food restaurants was also examined using network buffers centered at a participant's home and by counting the total number of fast-food restaurants reachable within 1600m (approximately 1 mile). Buffer distances were chosen based on our previous research and research showing buffer distances between $1200 \mathrm{~m}-1600 \mathrm{~m}$ are within a reasonable walking distance or a short bus ride/ drive. ${ }^{49-51}$ Based on previous research, a variable indicating a high density of fast-food restaurants was taken to be one when at least 5 fast-food restaurants (the sample median) were accessible within $1600 \mathrm{~m}$ of the participants home. ${ }^{33,49,51}$

Presence of a nearby convenience store-The NAICS codes 44512, 44711, and 44719 were used to identify convenience stores, including gas stations. A dichotomous measure was derived and taken to equal one when the distance to the nearest convenience store was less than $1200 \mathrm{~m}$ (a cut-off previously found to be related to BMI z-score and present for $88 \%$ of the sample). ${ }^{49}$

Presence of a nearby supermarket or super center-A list of local chain names was used to identify supermarkets (e.g., Cub Foods, Stillwater, MN) and super centers (e.g., SuperTarget, Target Brands, Inc., Minneapolis, MN). A dichotomous measure indicating the presence of a nearby outlet was derived to equal one when the distance to the nearest outlet was less than $2400 \mathrm{~m}$ (the median distance to the nearest supermarket found in the sample) ${ }^{49}$ and zero otherwise.

Overall summary score measures for family and neighborhood environments - In addition to the individual survey items/scales, an "Overall Summary Score" was created to summarize the supportive qualities of the home environment and the neighborhood built environment. A total of five measures are considered for the family environment and four for the neighborhood environment. To help facilitate interpretation of an overall effect of these specific variables, summary scores were created by summing dichotomized variables within the two domains so that higher values represent more supportive qualities for the home environment summary score and lower values represent more supportive qualities for the neighborhood environment summary score. All of the neighborhood environment variables were already dichotomous before summing, the family environment variables were first dichotomized at their median and then summed. When creating the summary scores there were two variables reverse coded: eating out family meals was reverse coded so that higher values indicated less eating out, and the nearby supermarket variable was reverse coded so that higher values indicated no nearby supermarket. The family environment summary score ranged from $0-5$ (mean $=3.0 \mathrm{SD}=1.3$ ) and neighborhood environment summary score ranged from $0-4$ (mean $=2.7, \mathrm{SD}=1.0)$, both scores were standardized for comparability in regression analyses.

\section{Statistical Analysis}

The associations of family and neighborhood environmental variables with BMI z-score, daily servings of fruits and vegetables, and weekly consumption of fast food were estimated 
using separate multiple regressions of each outcome on each environmental predictor, controlling for age, SES, and race/ethnicity. The beta estimate from each regression represents the mean difference in the outcome for individuals with the same control variables who are one unit different on the environmental predictor. Because of the use of individual household buffers to create neighborhood environmental variables specific to each individual, regression analyses are done at the individual level without the need for introducing a hierarchical statistical structure. Analyses were stratified by gender, based on previous research showing adolescents differ on dietary outcomes. ${ }^{52-54}$

To examine for interaction effects between the environmental and family variables on the outcomes, separate regressions were run for all combinations of family variables (i.e. family functioning, family meals, frequency of family eating out, parent encouragement for healthful eating, parent modeling of health eating) treated as continuous with neighborhood variable (i.e. high density of fast food restaurants, fast food restaurant within $1200 \mathrm{~m}$, convenience store within $1200 \mathrm{~m}$, and nearby supermarket, nearby convenience store, all treated as dichotomous. Analyses were stratified by gender. In total 120 ( 3 outcomes*4 neighborhood predictors $* 5$ family predictors $* 2$ genders) interactions were tested between neighborhood and family predictors. Six additional interactions were tested between the summary scores for neighborhood and family with the three different outcomes within both genders. Although the large number of tests might provoke the idea to correct for multiple testing, due to the still somewhat exploratory nature of this research and the reduced power associated with identifying interactions, a more liberal critical alpha value of 0.10 was used. Graphical presentation of some significant interactions are presented to facilitate interpretation where family variables are fixed at low and high values corresponding to their $25^{\text {th }}$ and $75^{\text {th }}$ percentiles. All analyses were performed in SAS (V9.2, Cary NC, 2011).

\section{RESULTS}

\section{Associations of home and neighborhood environment variables with adolescent outcomes}

BMI-Overall, there were several significant associations between characteristics of the family environment and adolescent BMI and few significant associations between the built neighborhood environment and BMI z-score for adolescents, after controlling for age, SES, and race/ethnicity (Tables 1-2). Specifically, for the family environment variables, higher frequency of family meals was associated with lower BMI z-score in adolescent boys (beta $=-0.03 ; \mathrm{p}=0.049$ ) and girls (beta $=-0.05 ; \mathrm{p}<0.001$ ). Higher family functioning and parent modeling of healthful eating was associated with lower BMI z-score for adolescent girls (beta $=-0.06 ; \mathrm{p}=0.02$ ). Additionally, frequency of family eating out was inversely associated with BMI z-score in adolescent boys ( $\mathrm{p}<0.05)$. There were no significant associations between the family summary score and BMI.

For the built environment variables, having a convenience store close was significantly associated with higher BMI z-score in adolescent girls (beta $=0.22 ; \mathrm{p}=0.005$ ) (Table 2) and having a riskier neighborhood score (i.e., neighborhood summary score) was associated with higher BMI z-score for adolescent boys (beta $=0.09 ; \mathrm{p}=0.007$ ). All other associations between the neighborhood built environment and adolescent girls' and boys' BMI z-scores were non-significant.

Fruit and vegetable intake-Overall, positive characteristics of the family environment (i.e., high family functioning, frequent family meals, high parent encouraging/modeling of healthful eating, high family summary score) were associated with higher fruit and vegetable intake for adolescent boys and girls, whereas, associations between aspects of the neighborhood built environment (i.e., high fast food, presence of a nearby convenience store or supermarket/super center) were minimal in relation to adolescent fruit and vegetable 
intake, after controlling for age, SES, and race/ethnicity (Tables 1-2). Specifically, for the family environment variables, higher frequency of family meals and parent encouraging and modeling of healthful eating was associated with more fruit and vegetable intake in adolescent boys (beta $=0.14,0.30,0.50$ respectively; $\mathrm{p}<0.001$ for all associations) and girls (beta $=0.14,0.31,0.43$ respectively; $\mathrm{p}<0.001$ ). Additionally, higher family functioning was associated with more fruit and vegetable intake for adolescent girls only (beta $=0.13 ; \mathrm{p}=$ $0.021)$. Higher frequency of family eating out was associated with more fruit and vegetable intake in adolescent boys (beta $=0.30 ; \mathrm{p}<0.001$ ) and girls (beta $=0.27 ; \mathrm{p}<0.001$ ). Furthermore, a high family summary score (i.e., higher is better environment) was associated with more fruit and vegetable intake in adolescent boys (beta $=0.28 ; \mathrm{p}<0.001$ ) and girls (beta $=0.33 ; \mathrm{p}<0.001$ ).

For the built environment variables, only having a convenience store nearby was significantly associated with higher fruit and vegetable intake in adolescent girls' (beta = $0.46, \mathrm{p}=0.021$ ) (Table 2). All other associations between the neighborhood built environment and adolescent girls' and boys' fruit and vegetable intake were non-significant.

Fast food consumption-Overall, positive characteristics of the family environment were associated with lower fast food consumption for adolescent boys and girls, while associations between aspects of the neighborhood built environment were minimal in relation to adolescent fast food consumption, after controlling for age, SES, and race/ ethnicity (Tables 1-2). Specifically, for the family environment variables, higher frequency of parent encouraging and modeling of healthful eating was associated with less fast food consumption in adolescent boys (beta $=-0.60$. -0.54 respectively; $\mathrm{p}<0.001$ ) and girls (beta $=-0.30,-0.16$ respectively; $\mathrm{p}<0.001)$. Additionally, higher family functioning was associated with less fast food consumption for adolescent boys (beta $=-0.39 ; \mathrm{p}<0.001$ ), but not girls. Higher frequency of family eating out was associated with higher fast food consumption for adolescent boys and girls $(\mathrm{p}<0.001)$. Furthermore, a higher family summary score was associated with less fast food consumption for adolescent boys (beta = $-0.87 ; \mathrm{p}<0.001)$ and girls (beta $=-0.52 ; \mathrm{p}<0.001)$.

For the built environment variables, only having a fast food restaurant close was significantly associated with higher fast food consumption in adolescent boys' (beta $=0.65$, $\mathrm{p}=0.017$ ) (Table 2). All other associations between the neighborhood built environment and adolescent girls' and boys' fast food consumption were non-significant.

\section{Combined influence of home and neighborhood environment variables on adolescent outcomes}

Although there were many nonsignificant interactions between the home and neighborhood environment variables, the eighteen (18/126) interactions that were statistically significant (eight interactions $\mathrm{p}<0.05$; ten interactions $\mathrm{p}<.10$ ) indicated that the associations between specific family environment characteristics and adolescents' dietary intake, fast food consumption and BMI were stronger when families lived in neighborhoods with more health-promoting qualities (a selection of significant interactions are shown in figure 1). For example, the associations between both higher family functioning in boys (beta $=0.06, \mathrm{p}=$ 0.047 ) and more frequent family meals in girls (beta $=0.20, \mathrm{p}<0.001$ ) and adolescent fruit and vegetable intake were enhanced when there was low density of fast food restaurants in the neighborhood (interaction test p-value boys $=0.094$, girls $=.019$ ) (Figures 1a-b).

Similarly, for girls with a supermarket nearby, parental encouragement for healthful eating (beta $=0.52, \mathrm{p}<0.001$ ) had a stronger association with fruit and vegetable intake than if the most accessible supermarket was far away (interaction test p-value $=.002$ ) (Figure 1c). Additionally, for adolescent boys, the positive association between parental encouragement 
(beta $=0.59, p>0.001)$ of healthful eating and more fruit and vegetable intake was stronger when the most accessible fast food restaurant was far away rather than when it was nearby (interaction test $\mathrm{p}$-value $=0.033$ ) (Figure 1d). Furthermore, for adolescent boys, the protective association between family meal frequency and adolescent boys' BMI (beta = $-0.05, \mathrm{p}=0.010$ ) was only seen in neighborhoods with low density of fast food (interaction test $\mathrm{p}$-value $=0.090)$ (Figure 1e). Similarly, in boys, there was a protective association between parental modeling of healthful eating with lower BMI z-score that was only seen in low density fast food neighborhoods (beta $=-0.04, p=0.009$, interaction test $p$-value $=$ 0.005 ) or neighborhoods with no convenience store nearby (beta modeling $=-.05, \mathrm{p}=$ 0.062 ; interaction test $\mathrm{p}$-value $=0.078$ ) (Figures $1 \mathrm{f}-\mathrm{g}$ ). Finally, when we consider the interaction between the summary scores for family and neighborhood on the three outcomes we find only one to be significant which was for boys' BMI z-score. The protective effect of higher family environment summary scores on BMI was found to be stronger in the neighborhoods with better built environment summary scores (interaction test $\mathrm{p}$-value $=$ 0.080 ).

Thus, the significant interactions between family environment and neighborhood characteristics, while exploratory in nature, suggest that supportive home environments have a stronger association with adolescent healthful dietary intake and BMI when they are coupled with healthful neighborhood environments.

\section{DISCUSSION}

The main aim of this study was to investigate whether and how the home environment and the neighborhood built environment are individually and jointly associated with adolescent fruit and vegetable intake, fast food consumption and BMI z-score. Results from the current study support previous research showing significant independent associations between a healthful home environment and more healthful dietary intake in adolescents, less fast food consumption and lower BMI z-score. ${ }^{12,14,23,55,56}$ Likewise, results confirm previous research showing minimal significant independent associations between the neighborhood built environment (e.g., many fast food restaurants, convenience stores) and healthful dietary intake and lower BMI in adolescents. ${ }^{27-29}$

The current study extends previous research by looking at the joint relationship between the home environment and the neighborhood built environment and adolescent dietary intake, fast food consumption and BMI z-score. Results, although exploratory in nature, suggest that living in a healthful neighborhood where there is low density fast food, close supermarkets, and convenience stores and fast food restaurants that are further away may enhance associations between a healthful home environment (i.e., high family functioning, frequent family meals, parent encouraging and modeling of healthful eating) and more healthful dietary intake, less fast food consumption, and lower BMI z-scores in adolescents. One possible explanation for these findings is that families who have supportive home environments, including frequent family meals, high family functioning, parental modeling and encouraging healthful eating, intentionally choose supportive neighborhoods, including low density fast food, close supermarkets and far away convenience stores and fast food restaurants, and the combination of these choices creates an additive benefit for their children's dietary patterns and BMI. Another explanation is that families with more supportive home environments live in higher socioeconomic status neighborhoods that also happen to have fewer fast food and convenience stores nearby.

Recent research has highlighted the complexity of adolescent obesity and the need to address the issue from multiple levels. ${ }^{57-59}$ Results from the current study support this idea and may inform adolescent obesity prevention efforts by identifying ways to tailor multi- 
level interventions with families of adolescents. For example, if families live in supportive neighborhood environments it may be important to focus interventions on helping parents to create a healthful home environment (e.g., frequent family meals and encouraging and modeling healthful eating is important) in order to benefit from the combined influence of a healthful home environment and neighborhood environment. If families live in unsupportive neighborhoods, it would be important to work with parents to help them counter the competing influences of the neighborhood (e.g., fast food restaurants, convenience stores) in addition to providing a home environment that is supportive of healthful eating.

There were some unexpected findings in the current study, including the frequency of family eating out being significantly associated with lower BMI z-score in adolescent boys and the closeness of a convenience store being significantly associated with higher fruit and vegetable intake in adolescent boys. Other research has shown that frequent family meals are associated with lower BMI overtime for adolescents. ${ }^{60}$ Thus, it may be the case that having a family meal, regardless of the location (e.g., home or at a restaurant) is protective for adolescent BMI. Additionally, the positive association between proximity to a convenience store and adolescent fruit and vegetable intake may be a result of some convenience stores now carrying more fresh produce such as fruits and vegetables. ${ }^{30,61}$ However, it remains unclear as to the specific mechanism(s) for these unexpected associations.

Study strengths and limitations should be taken into account when interpreting the study findings. The current study has several strengths, including the use of a large, diverse, population-based sample. An additional strength of the study is that several of the variables were directly measured, limiting the potential for self-report bias. Specifically, heights and weights were directly measured and a comprehensive set of objectively measured neighborhood characteristics were derived based on state-of-the-art, standardized GIS protocols centered at participants' home residences. There are also potential study limitations. First, all participants were drawn from 20 schools within two metropolitan school districts, thus, lack of variability between schools and neighborhoods may have limited our ability to detect associations. Additionally, the data are cross-sectional, limiting our ability to infer causal relationships. Another limitation is the use of self-report measures for gathering dietary intake, however, food frequency questionnaires have been found to highly correlate with objectively measured 24 -hour dietary recalls. ${ }^{41,42,62}$ Furthermore, although several measures were taken from scales, some of the items were single-item measures and three of the items had moderate (i.e., < 0.50 ) test-retest reliability correlations (i.e., fruit and vegetable intake and fast food consumption) and one scale had moderate internal consistency (i.e., 0.58). There may also be possible classification and address errors in the GIS data ${ }^{63,64}$ Finally, because of the many interaction tests, and several nonsignificant interaction findings, it is important to remember these results are exploratory.

Future research should look at other levels of influence on the family environment in adolescents' lives, such as school, work and peer influences in order to get a more comprehensive picture of the multiple levels of influence that contribute to adolescent obesity. In addition, multi-level, longitudinal studies are important in order to identify predictors of adolescent obesity on multiple levels. Furthermore, studies that compare interventions that focus on the neighborhood environment only, the family environment only, or both together would be important to carry out in order to confirm results from the current study. 


\section{CONCLUSIONS}

Results of the current study indicate that the association between a healthful home environment and adolescent healthier dietary intake and lower BMI may be enhanced when coupled with healthful neighborhood environments. Thus, it may be important for prevention efforts to tailor interventions for adolescents who live in certain environments that help or hinder their efforts for a healthful home environment in order to be more effective in reducing adolescent obesity. Additionally, findings from this study suggest that it may be important for public health interventions to simultaneously target the both the home and the neighborhood environments of adolescents in order to have the greatest impact on adolescent obesity prevention.

\section{Acknowledgments}

Research is supported by grant number R01 HL093247 from the National Heart, Lung, and Blood Institute (PI: Dianne Neumark-Sztainer). Dr. Wall is supported by a grant from the National Institutes of Health (U01HD061940). The content is solely the responsibility of the authors and does not necessarily represent the official views of the National Heart, Lung and Blood Institute, the National Institute of Child Health and Human Development, the National Cancer Institute or the National Institutes of Health.

\section{References}

1. Bethell C, Simpson L, Stumbo S, Carle AC, Gombojav N. National, State and Local Disparities in Childhood Obesity. Health Affairs. 2010; 29(3):347-356. [PubMed: 20194972]

2. Wilson DK. New perspectives on health disparities and obesity interventions in youth. Journal of Pediatric Psychology. 2009; 34(3):231-244. [PubMed: 19223277]

3. NIH. Reducing health disparities among children: Strategies and programs for health plans. Washington DC: 2007.

4. Ogden C, Lamb M, Carroll M, Flegal K. Obesity and Socioeconomic status in children and adolescents: United Stated, 2005-2008. NCHS Data Brief. 2010; (51)

5. Ogden C, Carroll M, Curtin L, Lamb M, Flegal K. Prevalence of high body mass index in US children and adolescents, 2007-2008. Journal of the American Medical Association. 2010; 303(3): 8.

6. Striegel-Moore RH, Thompson DR, Affenito SG, et al. Fruit and vegetable intake: Few adolescent girls meet national guidelines. Preventive medicine. 2006; 42(3):223-228. [PubMed: 16406116]

7. Kimmons J, Gillespie C, Seymour J, Serdula M, Blanck HM. Fruit and vegetable intake amont adolescents and adults in the United States: Percentage meeting individualized recommmendations. The Medscape Journal of Medicine. 2009; 11(1)

8. Bowman SA, Gortmaker SL, Ebbeling CB, Pereira MA, Ludwig DS. Effects of fast-food consumption on energy intake and diet quality among children in a national household survey. Pediatrics. 2004; 113:112-118. [PubMed: 14702458]

9. Paeratakul S, Ferdinand DP, Champagne CM, Ryan DH, Bray GA. Fast-food consumption among US adults and children: Dietary and nutrient intake profile. Journal of the American Dietetic Association. 2003; 103(10):1332-1338. [PubMed: 14520253]

10. Bauer KW, Larson NI, Nelson MC, Story M, Neumark-Sztainer D. Fast food intake among adolescents: Secular and longitudinal trends from 1999 to 2004. Preventive medicine. 2009; 48(3): 284-287. [PubMed: 19166872]

11. National Institutes of Health Obesity Research Task Force. Strategic plan for NIH obesity research. Bethesda, MD: U.S. Department of Health and Human Services, National Institutes of Health; 2011. p. 11-5493.

12. Berge J, Wall M, Bauer K, Neumark-Sztainer D. Parenting characteristics in the home environment and adolescent overweight: A latent class analysis. Obesity. 2009; 18(4):818-825. [PubMed: 19816417] 
13. Berge JM, Wall M, Loth K, Neumark-Sztainer D. Parenting style as a predictor of adolescent weight and weight-related behaviors. Journal of Adolescent Health. 2010; 46(4):331-338. [PubMed: 20307821]

14. Berge JM. A review of familial influences on child and adolescent obesity: What has the $21^{\text {st }}$ century taught us so far. International Journal of Adolescent Medicine and Health. 2009; 21(4): 546-561.

15. Videon TM, Manning CK. Influences on adolescent eating patterns: The importance of family meals. Journal of Adolescent Health. 2003; 32(365-373)

16. Neumark-Sztainer DLN, Fulkerson JA, Eisenberg ME, Story M. Family meals and adolescents: What have we learned from Project EAT (Eating Among Teens). Public Health Nutrition. 2010; 13:1113-1121. [PubMed: 20144257]

17. Neumark-Sztainer DHP, Story M, Croll J, Perry C. Family meal patterns: Associations with sociodemographic characteristics and improved dietary intake among adolescents. J Am Diet Assoc. 2003; 103(3):317-322. [PubMed: 12616252]

18. Berge JMWM, Neumark-Sztainer D, Larson N, Story M. Parenting style and family meals: Crosssectional and 5-year longitudinal associations. J Am Diet Assoc. 2010; 110(7):1036-1042. [PubMed: 20630160]

19. Berge JMWM, Bauer KW, Neumark-Sztainer D. Parenting characteristics in the home environment and adolescent overweight: a latent class analysis. Obesity (Silver Spring). 2010; 18(4):818-825. [PubMed: 19816417]

20. Berge JMWM, Loth K, Neumark-Sztainer D. Parenting style as a predictor of adolescent weight and weight-related behaviors. J Adolesc Health. 2010; 46(4):331-338. [PubMed: 20307821]

21. Berge JM, Wall M, Larson N, Loth K, Neumark-Sztainer D. Family Functioning: Associations with weight status, eating behaviors, and physical activity in adolescentsa. Journal of Adolescent Health. Submitted.

22. Wardle J, Sanderson S, Guthrie CA, Rapoport L, Plomin R. Parental feeding style and the intergenerational transmission of obesity risk. Obesity Research. 2002; 10(6):453-462. [PubMed: 12055321]

23. Bauer KW, Neumark-Sztainer D, Fulkerson J, Hannan P, Story M. Familial correlates of adolescent girls' physical activity, television use, dietary intake, weight, and body composition. International Journal of Behavioral Nutrition and Physical Activity. 2011; 8:25-31. [PubMed: 21453516]

24. Bauer KW, Nelson MC, Boutelle KN, Neumark-Sztainer D. Parental influences on adolescents' physical activity and sedentary behavior: Longitudinal findings from Project EAT-II. International Journal of Behavioral Nutrition and Physical Activity. 2008; 5:12. [PubMed: 18302765]

25. Rhee KE, Lumeng JC, Appugliese DP, Kaciroti N, Bradley RH. Parenting styles and overweight status in first grade. Pediatrics. 2006; 117:2047-2054. [PubMed: 16740847]

26. Rhee KE. Childhood overweight and the relationship between paren behaviors, parenting style, and family functioning. The Annals of the American Academy of Political and Social Science. 2008; 615:11-37.

27. Morland K, Wing S, Diez Roux A, Poole C. Neighborhood characteristics associated with the location of food stores and food service places. American Journal of Preventive Medicine. 2002; 22(1):23-29. [PubMed: 11777675]

28. Morland K, Wing S, Diez Roux A. The contextual effect of the local food environment on residents' diets: the atherosclerosis risk in communities study. American Journal of Public Health. 2002; 92(11):1761-1767. [PubMed: 12406805]

29. Morland K, Diez Roux AV, Wing S. Supermarkets, other food stores, and obesity: the atherosclerosis risk in communities study. American Journal of Preventive Medicine. 2006; 30(4): 333-339. [PubMed: 16530621]

30. Bodor J, Rose D, Farley T, Swalm C, Scott S. Neighborhood fruit and vegetable availability and consumption: the role of small food stores in an urban environment. Public Health Nutrition. 2008; 11(4):413-420. [PubMed: 17617930] 
31. Jago R, Baranowski T, Baranowski JC, Cullen KW, Thompson D. Distance to food stores \& adolescent male fruit and vegetable consumption: mediation effects. The international journal of behavioral nutrition and physical activity. 2007; 4:35. [PubMed: 17850673]

32. Sallis, JF.; Owen, N.; Fisher, EB. Ecological models of health behavior. In: Glanz, K.; Rimer, BK.; Viswanath, K., editors. Health Behavior and Health Education: Theory, Research, and Practice. 4th ed.. San Francisco, CA: Josey-Bass; 2008. p. 465-485.

33. McLeroy KR, Bibeau D, Steckler A, Glanz K. An ecological perspective on health promotion programs. Health Education Quarterly. 1988; 15(4):351-377. [PubMed: 3068205]

34. Neumark-Sztainer D, Story M, Perry C, Casey M. Factors influencing food choices of adolescents: findings from focus-group discussions with adolescents. J Am Diet Assoc. 1999; 99(8):929-937. [PubMed: 10450307]

35. Neumark-Sztainer D, Croll J, Story M, Hannan PJ, French SA, Perry C. Ethnic/racial differences in weight-related concerns and behaviors among adolescent girls and boys: findings from Project EAT. J Psychosom Res. 2002; 53(5):963-974. [PubMed: 12445586]

36. Sallis, J.; Owen, N.; Fisher, E. Ecological models of health behavior. In: Glanz, K.; Rimer, B.; Viswanath, K., editors. Health Behavior and Health Education: Theory, Research, and Practice. 4th ed.. San Francisco: Jossey-Bass; 2008. p. 465-485.

37. Bandura, A. Social foundations of thought and action: A social cognitive theory. Englewood Cliffs, NJ: Prentice-Hall; 1986.

38. Epstein NB, Baldwin LM, Bishop DS. The McMaster Family Assessment Device. Journal of Marital and Family Therapy. 1983; 9(2):171-180.

39. Miller IW, Epstein NB, Bishop DS, Keitner GI. The McMaster Family Assessment Device: Reliability and validity. Journal of Marital and Family Therapy. 1985; 11:345-356.

40. Cullen KW, Baranowski T, Rittenberry L, Cosart C, Herbert D, deMoor C. Child-reported family and peer influences on fruit, juice and vegetable consumption: Reliability and validity of measures. Health Education Research. 2001; 16(2):187-200. [PubMed: 11345661]

41. Rockett HRH, Breitenbach MA, Frazier AL, et al. Validation of a youth/adolescent food frequency questionnaire. Preventive medicine. 1997; 26(6):808-816. [PubMed: 9388792]

42. Rockett HR, Wolf AM, Colditz GA. Development and reproducibility of a food frequency questionnaire to assess diets of older children and adolescents. Journal of the American Dietetic Association. 1995; 95(3):336-340. [PubMed: 7860946]

43. Kuczmarski RJ, Ogden CL, Guo SS, et al. 2000 CDC Growth Charts for the United States: methods and development. Vital Health Stat. 2002; Series 11(246):1-190.

44. Neumark-Sztainer D, Maclehose R, Loth K, Fulkerson JA, Eisenberg ME, Berge J. What's for dinner? Types of food served at family dinner differ across parent and family characteristics. Public Health Nutr. 2012 Oct 19.:1-11. [PubMed: 23083836]

45. Neumark-Sztainer D, Story M, Hannan PJ, Croll J. Overweight status and eating patterns among adolescents: Where do youth stand in comparison to the Healthy People 2010 Objectives? American Journal of Public Health. 2002; 92(5):844-851. [PubMed: 11988458]

46. Sherwood NE, Wall M, Neumark-Sztainer D, Story M. Effect of socioeconomic status on weight change patterns in adolescents. Preventing Chronic Disease. 2009; 6(1)

47. Esri Business Analyst Desktop. [Online]. http://www.esri.com/software/arcgis/extensions/ businessanalyst/.

48. Forsyth A, Larson N, Lytle L, et al. LEAN-GIS Protocols: Local Environment for Activity and Nutrition - - Geographic Information Systems. Version 2.1. 2012 http://www.designforhealth.net/ pdfs/LEAN_Protocol_V2_1_010112rev.pdf.

49. Wall MM, Larson NI, Forsyth A, et al. Patterns of obesogenic neighborhood characteristics and adolescent weight status. American Journal of Preventive Medicine. 2012; 42(5):e65-e75. [PubMed: 22516505]

50. Colabianchi N, Dowda M, Pfeiffer KA, Porter DE, Almeida MJ, Pate RR. Towards an understanding of salient neighborhood boundaries: adolescent reports of an easy walking distance and convenient driving distance. The international journal of behavioral nutrition and physical activity. 2007; 4:66. [PubMed: 18088416] 
51. Larson N, Wall M, Story M, Neumark-Sztainer D. Home/family, peer, school, and neighborhood correlates of obesity in adolescents: A multilevel analysis. Obesity. 2013; 21(9):1858-1869. [PubMed: 23512596]

52. Neumark-Sztainer D, Hannan PJ. Weight-related behaviors among adolescent girls and boys: Results from a national survey. Arch Pediatr Adolesc Med. 2000; 154(6):569-577. [PubMed: 10850503]

53. Neumark-Sztainer D, Wall M, Hannan PJ, Story M, Croll J, Perry C. Correlates of fruit and vegetable intake among adolescents: Findings from Project EAT. Prev Med. 2003; 37(3):198-208. [PubMed: 12914825]

54. Larson NI, Neumark-Sztainer D, Hannan PJ, Story M. Trends in adolescent fruit and vegetable consumption, 1999-2004: Project EAT. American Journal of Preventive Medicine. 2007; 32:147150. [PubMed: 17234489]

55. Berge JM, Wall M, Larson N, Loth K, Neumark-Sztainer D. Family functioning: Associations with weight status, eating behaviors and physical activity in adolescents. Journal of Adolescent Health. in press.

56. Larson NI, Neumark-Sztainer D, Hannan PJ, Story M. Family meals during adolescence are associated with higher food quality and healthful meal patterns during young adulthood. Journal of the American Dietetic Association. 2007; 107:1502-1510. [PubMed: 17761227]

57. Huang TTDA, Kumanyika S, Glass TA. A systems-oriented multilevel framework for addressing obesity in the 21st century. Prev Chronic Dis. 2009; 6(3):A82. [PubMed: 19527584]

58. Huang TT, Glass TA. Transforming research strategies for understanding and preventing obesity. JAMA. 2008 Oct 15; 300(15):1811-1813. [PubMed: 18854544]

59. Huang TT. Solution-oriented research: Converging efforts of promoting environmental sustainability and obesity prevention. American Journal of Preventive Medicine. 2009; 36:S60S62. [PubMed: 19147062]

60. Berge J, Wall M, Tsun-Fang F, Fulkerson J, Larson N, Neumark-Sztainer D. The protective role of family meals for youth: 10-year associations between family meal frequency and obesity. Under Review.

61. Pearce A, Kirk C, Cummins S, et al. Gaining children's perspectives: a multiple method approach to explore environmental influences on healthy eating and physical activity. Health \& place. 2009 Jun; 15(2):614-621. [PubMed: 19083258]

62. Perks SM, Roemmich JN, Sandow-Pajewski M, et al. Alterations in growth and body composition during puberty. IV. Energy intake estimated by the youth-adolescent food-frequency questionnaire: Validation by the doubly labeled water method. American Journal of Clinical Nutrition. 2000; 72(6):1455-1460. [PubMed: 11101471]

63. Brownson R, Hoehner C, Day K, Forsyth A, Sallis J. Measuring the built environment for physical activity. State of the science. Am J Prev Med. 2009; 36(4S):S99-S123. [PubMed: 19285216]

64. Forsyth A, Lytle L, Van Riper D. Finding food: Issues and challenges in using Geographic Information Systems to measure food access. J Transp Land Use. 2010; 3(1):43-65. [PubMed: 21837264] 


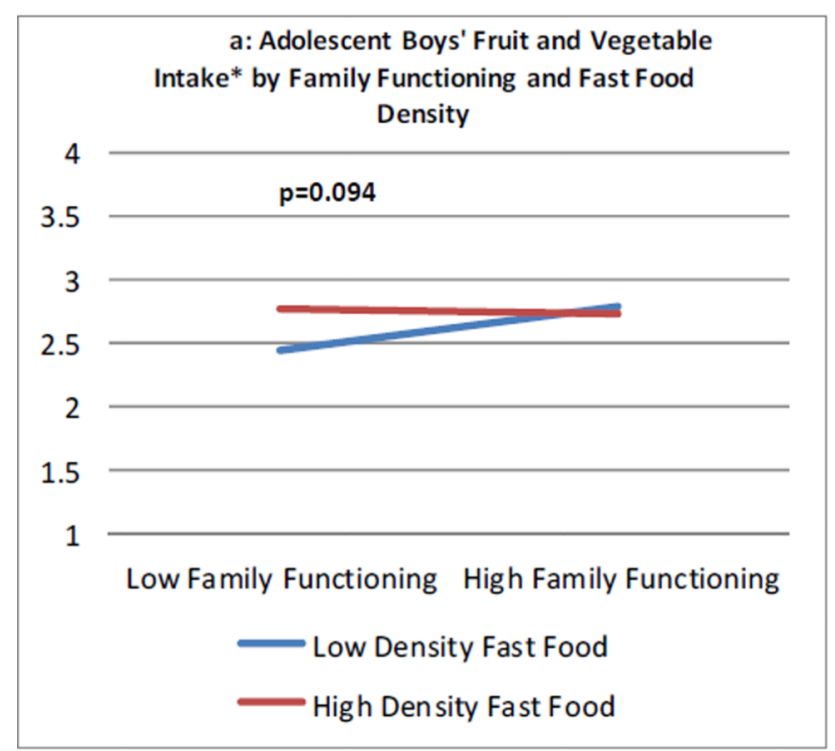

$p=0.019$ 

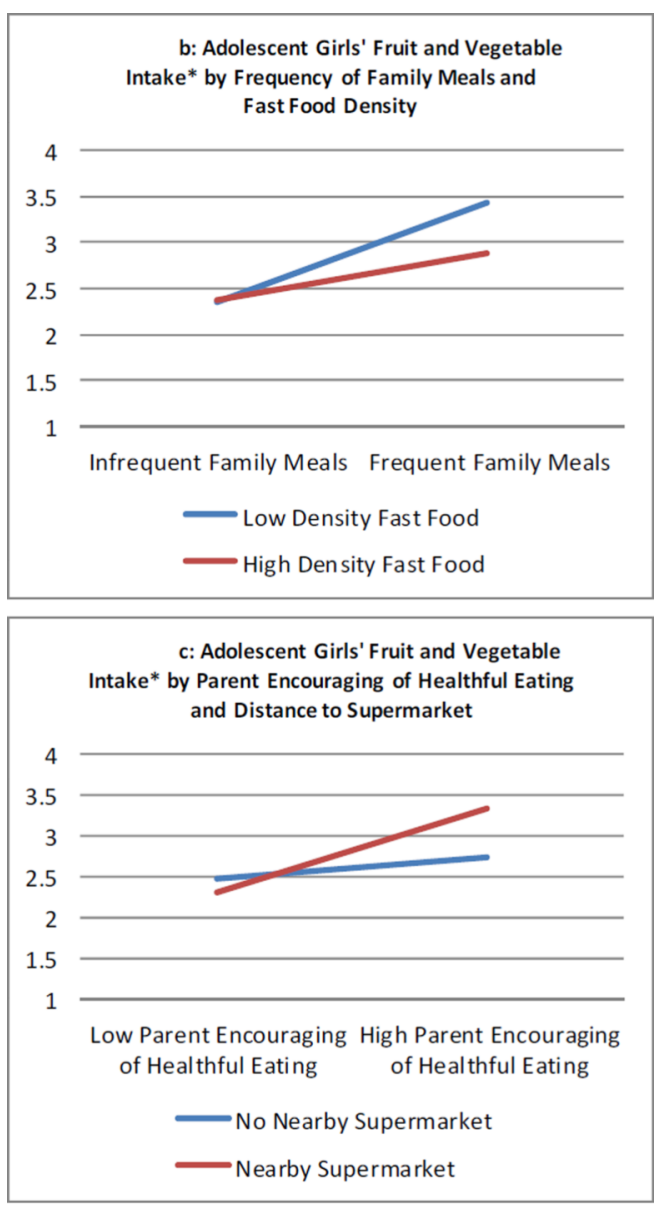

$p=0.094$

$p=0.094$ 


\section{d: Adolescent Boys' Fruit and Vegetable Intake* by Parent Encouraging of Healthful Eating and Distance to Fast Food Restaurant}

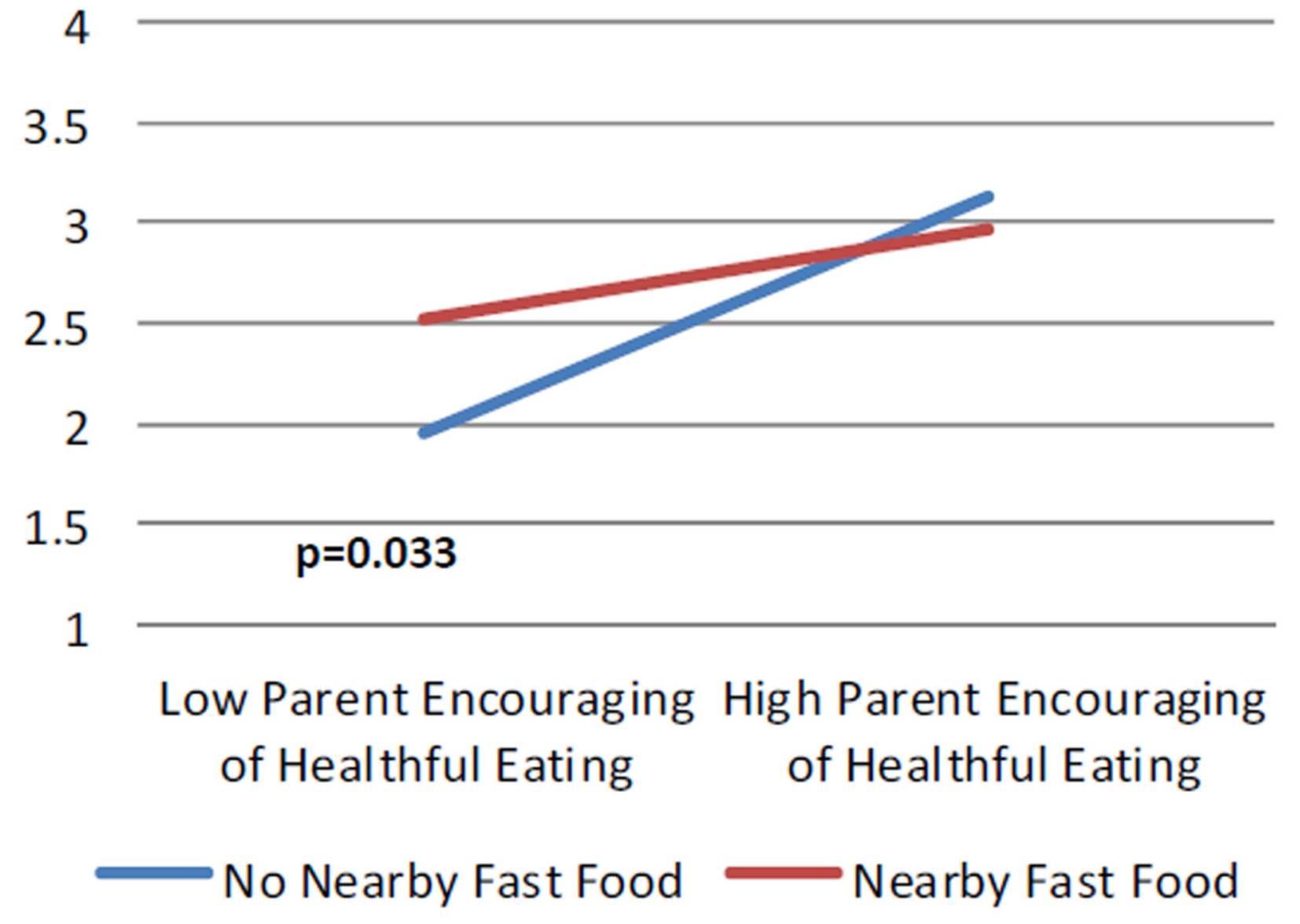

*y-axis = daily servings of fruits and vegetables. 

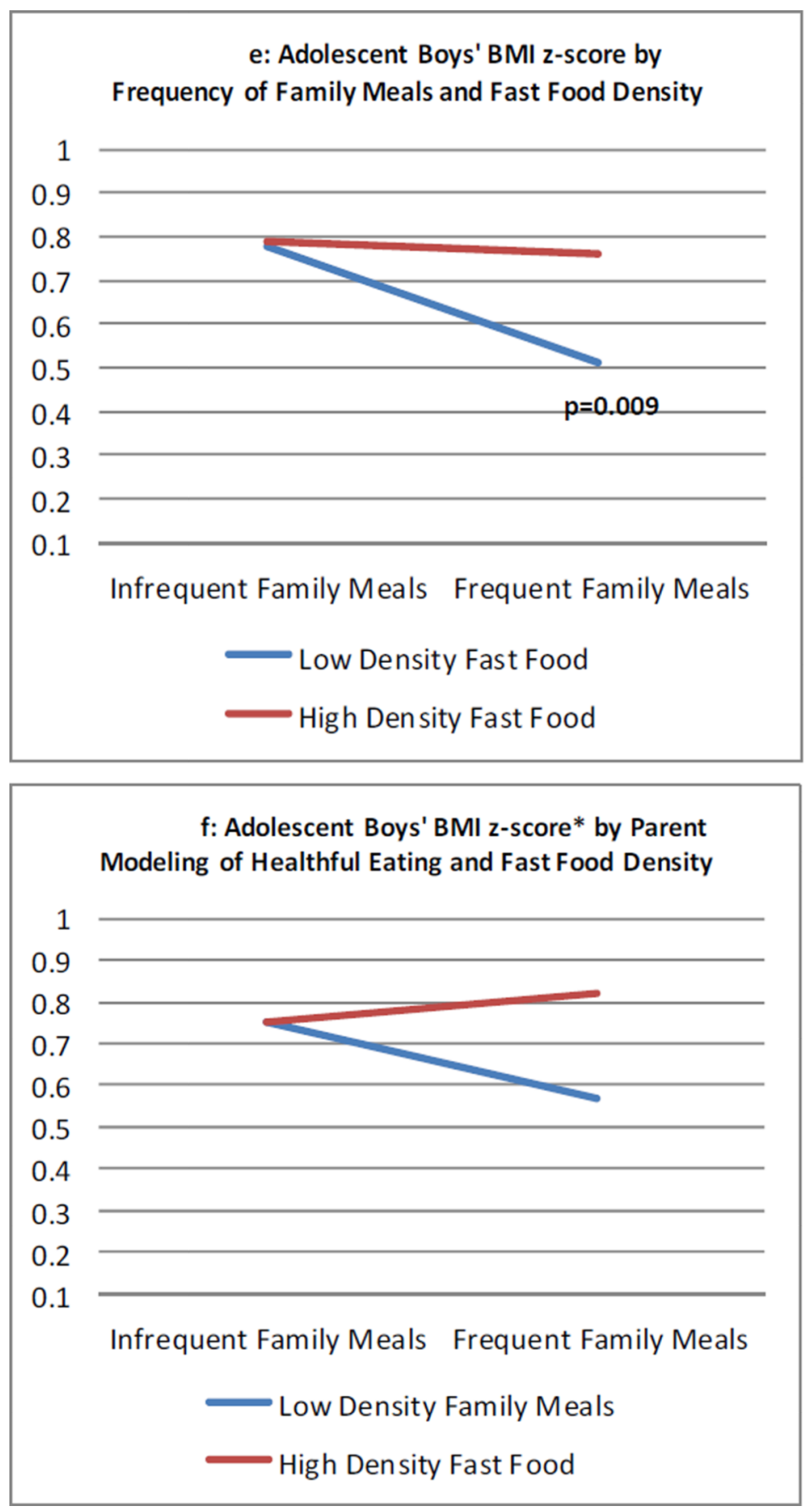


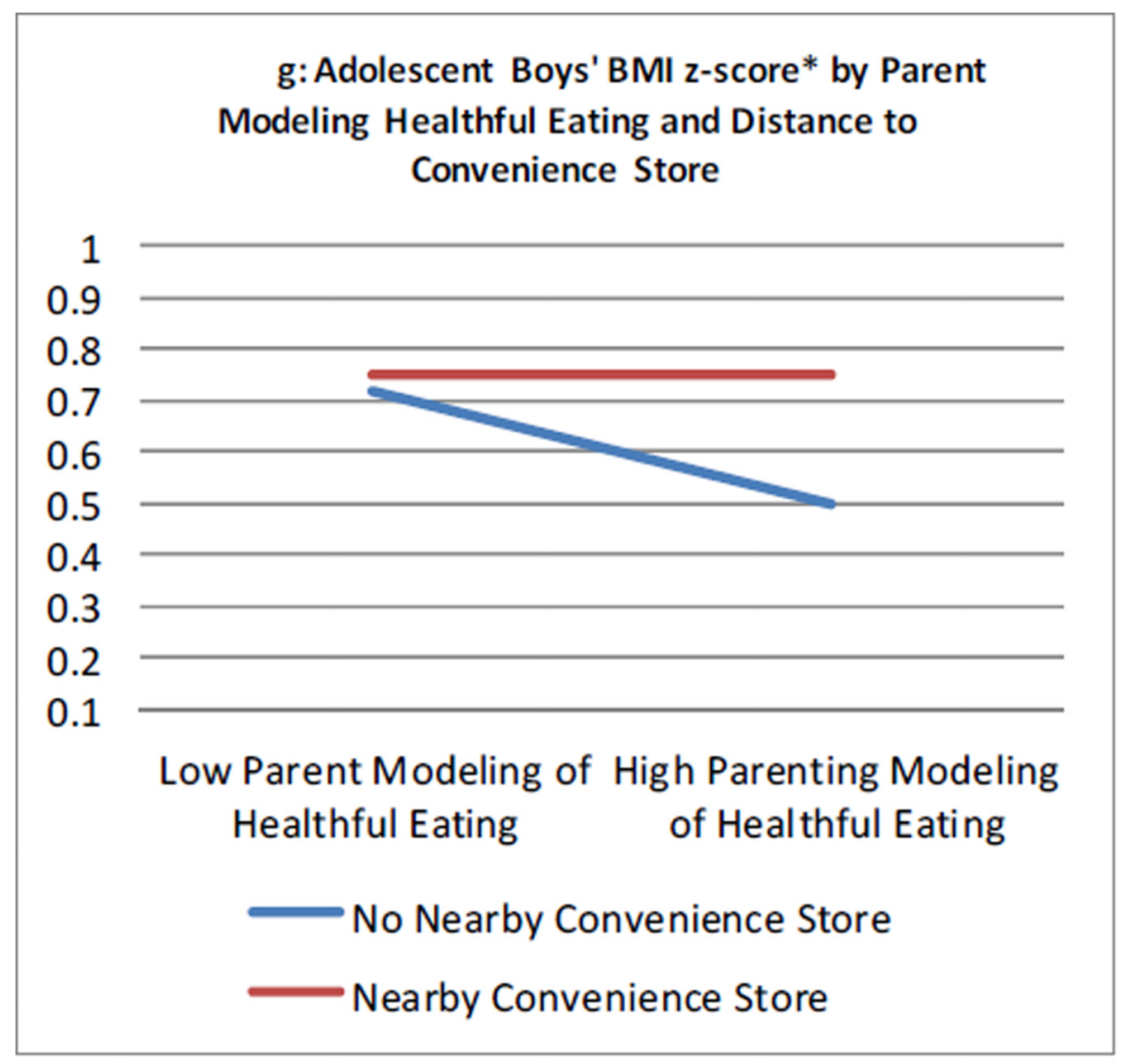

$$
* y \text {-axis }=\text { BMI z-score }
$$

Figure 1.

a-d: Interactions between Family Home Environment Variables and Neighborhood Environment Variables on Adolescent Fruit and Vegetable Intake

e-g: Interactions between Family Home Environment Variables and Neighborhood Environment Variables on Adolescent BMIz 


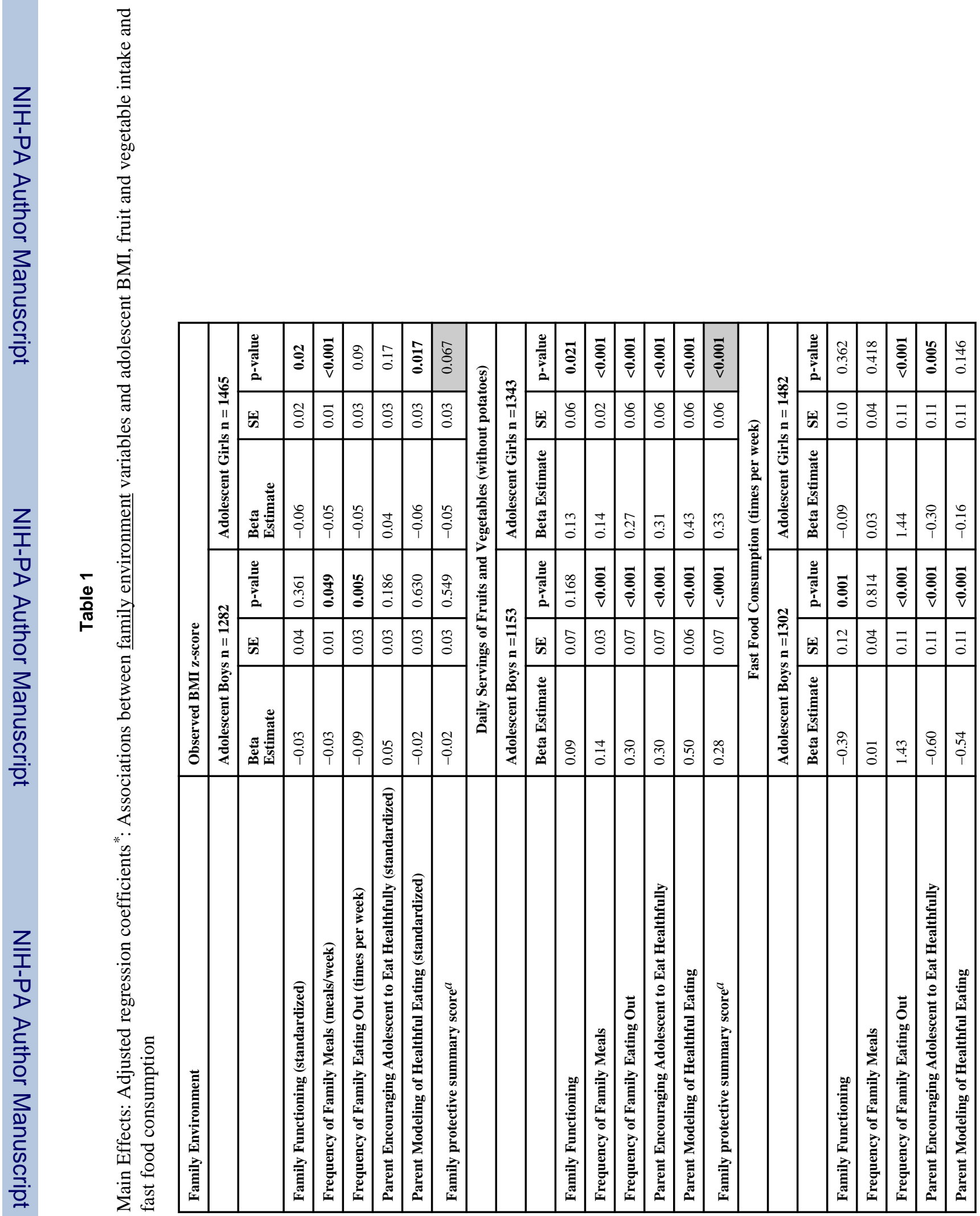




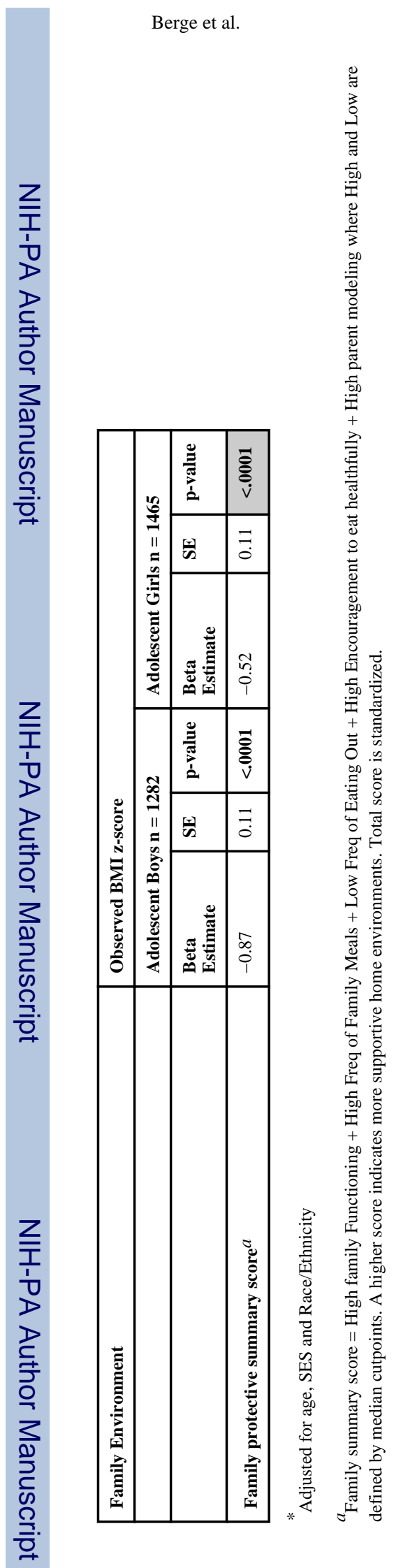

Page 21

Health Place. Author manuscript; available in PMC 2015 March 01. 


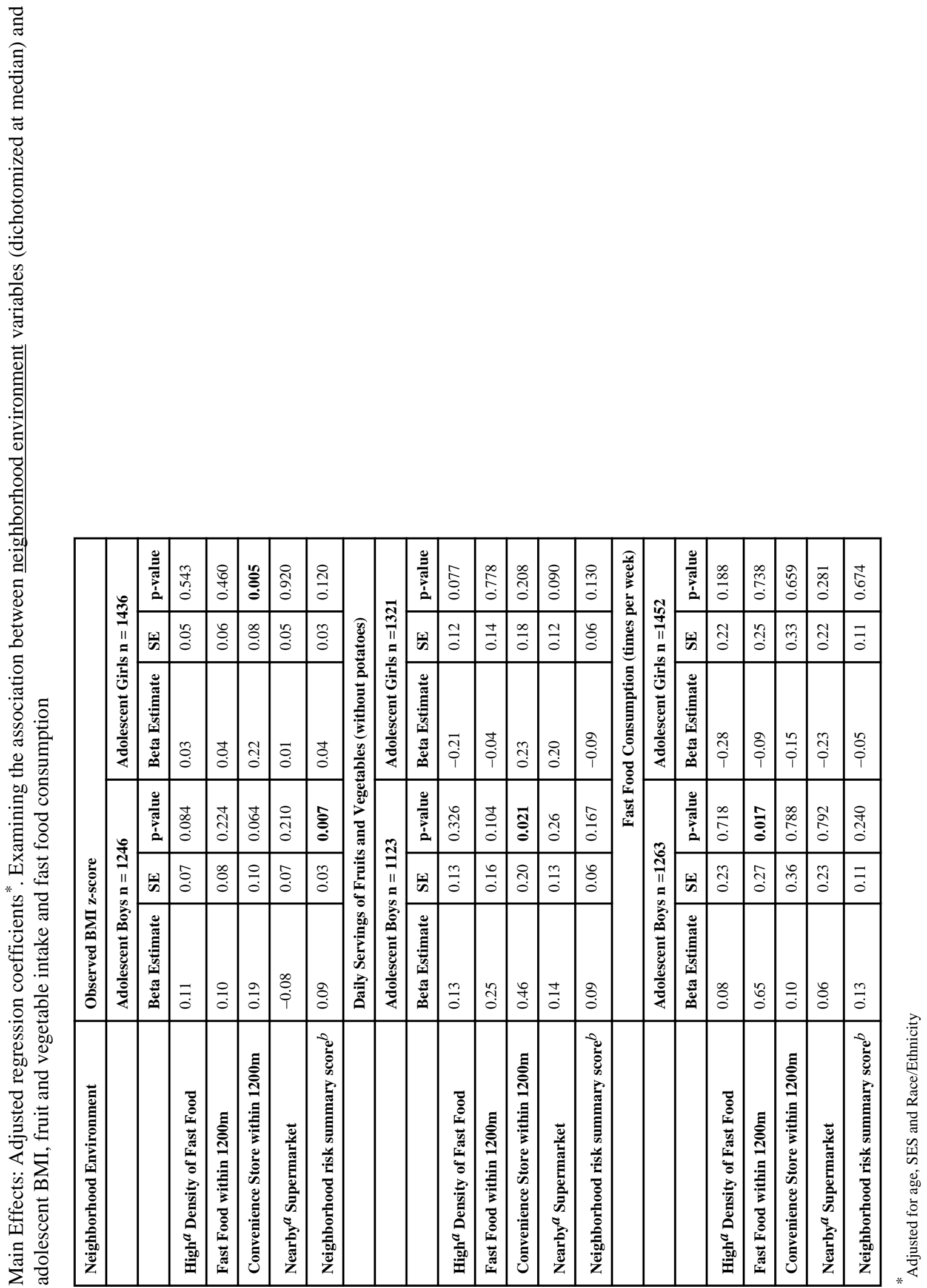




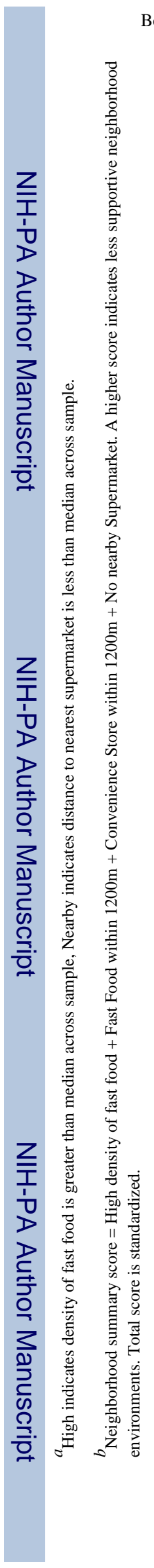

Berge et al.

Page 23

Health Place. Author manuscript; available in PMC 2015 March 01. 